\title{
Drought stress effects on wheat are mitigated by atmospheric $\mathrm{CO}_{2}$ enrichment
}

\author{
Remy MANDERSCHEID*, Hans-Joachim WEIGEL \\ Institute of Agroecology, Federal Agricultural Research Centre, Bundesallee 50, 38116 Braunschweig, Germany
}

(Accepted 7 December 2006)

\begin{abstract}
The atmospheric $\mathrm{CO}_{2}$ concentration is predicted to increase and to generate a rise in the global surface temperature, and change the seasonal precipitation pattern. This could aggravate the severity of summer drought conditions and affect crop yield. We studied the effect of the interaction of $\mathrm{CO}_{2}$ and water supply on seasonal absorption of photosynthetically active radiation and radiation-use efficiency of aboveground biomass production to understand the processes contributing to final yield. Wheat was grown over two years in open-top chambers at present or future (+280 ppmv) atmospheric $\mathrm{CO}_{2}$ concentration and under sufficient water supply or drought stress in lysimeters with a soil depth of $0.4 \mathrm{~m}$ (first year) or in the field with unrestricted root growth (second year). Drought stress was started after the first node stage by halving the water supply. Our results show that under sufficient watering, $\mathrm{CO}_{2}$ enrichment did not affect the green area index or seasonal radiation absorption. Drought stress always decreased the green area index and accelerated canopy senescence, which in the second year resulted in a decrease of $23 \%$ in the seasonal radiation absorption under the present atmospheric $\mathrm{CO}_{2}$ concentration. $\mathrm{CO}_{2}$ enrichment stimulated the green area index under drought stress in the second year and seasonal radiation absorption was only decreased by $16 \%$. Radiation-use efficiency was reduced by drought and increased by $\mathrm{CO}_{2}$ elevation and the $\mathrm{CO}_{2}$ effect was higher under restricted $(+60 \%)$ than under sufficient watering $(+32 \%)$. This implies that $\mathrm{CO}_{2}$ enrichment enhanced final biomass and grain yield by less than $10 \%$ under well-watered conditions and by more than $44 \%$ under drought stress conditions, respectively. This study indicates that the increase in atmospheric $\mathrm{CO}_{2}$ concentration will attenuate the effects of summer drought on wheat grain yield.
\end{abstract}

$\mathrm{CO}_{2}$ enrichment / drought / leaf area index / radiation absorption / radiation-use efficiency / water-use efficiency / wheat

\section{INTRODUCTION}

The atmospheric $\mathrm{CO}_{2}$ concentration is increasing and is predicted to double by the end of this century as compared with the pre-industrial level (Houghton et al., 2001). Besides its direct effect on plant growth, this change is expected to raise the global mean surface temperature and to result in an increase in the severity of summer drought conditions (Gregory et al., 2003). This is in line with the finding of Foulkes et al. (2001) that already today drought is more common than is currently supposed in the temperate climate of Europe. This has consequences for agricultural production, since water shortage results in a substantial reduction in crop growth and yield (Foulkes et al., 2001; Jamieson et al., 1995).

Soil drought is often quantified by measuring the amount of plant-available soil water (Sadras and Milroy, 1996). Plant responses under drought can be closely related to available water. It has been demonstrated that the decrease in available water under drought stress first affects leaf expansion and then stomatal conductance and gas exchange (Sadras and Milroy, 1996). The cessation of leaf area growth at low available water levels and the accelerated senescence of the existing leaves result in a decrease in radiation absorption by the green canopy (Brisson and Casals, 2005; Foulkes et al., 2001; Jamieson et al., 1998; O'Connell et al., 2004). This process

* Corresponding author: remy.manderscheid@ fal.de and the decrease in radiation-use efficiency due to the reduction in stomatal conductance (Foulkes et al., 2001; Jamieson et al., 1995) are responsible for the growth reduction under drought. However, it seems that drought stress reduces plant growth more through a reduction of the amount of radiation intercepted than reduced radiation-use efficiency (Brisson and Casals, 2005; Jamieson et al., 1998; O’Connell et al., 2004).

There is still only a limited number of experiments on the combined effect of different levels of watering and of atmospheric $\mathrm{CO}_{2}$ concentrations on plant growth, especially under field-related conditions (Idso and Idso, 1994). Experiments on the interaction effect of $\mathrm{CO}_{2}$ enrichment and water supply on growth and yield of $\mathrm{C}_{3}$ crops mostly indicated a relatively higher $\mathrm{CO}_{2}$ response when water was limited (Chaudhuri et al., 1990; Kang et al., 2002; Mitchell et al., 2001; Sionit et al., 1980) and even a significant positive interaction (Baker et al., 1997; Gifford, 1979; Rogers et al., 1986). In a recent field study, grain yield of wheat grown at $550 \mathrm{ppm}$ $\mathrm{CO}_{2}$ was increased by $8 \%$ and $21 \%$ under sufficient and limited water supplies, respectively (Kimball et al., 1995).

The interaction effect of water supply and atmospheric $\mathrm{CO}_{2}$ concentration on plant growth can be explained by two main mechanisms: (i) the assimilation hypothesis, which includes the effect of drought and $\mathrm{CO}_{2}$ concentration on photosynthesis via their effect on stomatal conductance, and (ii) a wateruse optimization hypothesis. The latter hypothesis means that 
the water status of plants under high $\mathrm{CO}_{2}$ is not so strongly impaired by drought stress because of lower soil water consumption, as a consequence of a decrease in stomatal and canopy conductance and the exploitation of additional water resources by an increase in root growth (Polley, 2002). The magnitude of the positive interaction due to (i) depends on the extent to which crop photosynthesis and growth are limited by conductance under drought conditions. The assimilation hypothesis is based on the curvilinear relationship between stomatal conductance and the net photosynthetic rate, which results in an enhancement of water-use efficiency under drought (Andre and Du Cloux, 1993; Foulkes et al., 2001). If water shortage decreases stomatal conductance under ambient and high $\mathrm{CO}_{2}$ concentrations to a similar extent, the resulting decrease in $\mathrm{CO}_{2}$ assimilation will be lower under elevated than under ambient atmospheric $\mathrm{CO}_{2}$ concentration. Moreover, the positive effect of $\mathrm{CO}_{2}$ enrichment on photosynthesis and water-use efficiency will be even higher, as stomatal conductance is more reduced by water stress (Andre and Du Cloux, 1993). If the increased response to $\mathrm{CO}_{2}$ under drought is due to this mechanism, crop growth response to $\mathrm{CO}_{2}$ could be described primarily by an increase in radiation-use efficiency. However, if the second mechanism is also true, the increased response to $\mathrm{CO}_{2}$ under drought should be connected to a higher green area index and light absorption, since leaf area expansion is very sensitive to cell turgor, and consequently, to the plant water status.

Experimental evidence which supports these two hypotheses is scarce and contradictory. Clifford et al. (1993) found that the higher $\mathrm{CO}_{2}$ effect on growth of groundnut under drought stress as compared with well-watered conditions was primarily mediated by an increase in radiation-use efficiency, while the effect on radiation absorption was small. However, in a field study with cotton, increase in radiation-use efficiency and absorption of photosynthetically active radiation by $\mathrm{CO}_{2}$ elevation was not modified by water supply (Pinter et al., 1994). Radiation-use efficiency is an important parameter used by many plant growth models to simulate photosynthesis (Jamieson et al., 1998).

In a previous paper (Burkart et al., 2004), it has been shown that $\mathrm{CO}_{2}$ enrichment decreased canopy evapotranspiration under well-watered conditions, while under drought stress, canopy water flux was unaffected or even increased due to a stimulation of root growth in the deeper soil layers. The objective of the present study was to examine the effects of $\mathrm{CO}_{2}$ and water supply on radiation absorption by evaluating green leaf and stem area growth and senescence, on the radiation-use efficiency of aboveground biomass production and on grain yield of wheat. Here we report on the findings from an open-top chamber study, in which wheat was grown over two years under two $\mathrm{CO}_{2}$ and watering levels.

\section{MATERIALS AND METHODS}

\subsection{Plant cultivation}

In 1998, spring wheat, Triticum aestivum cv. Minaret, was grown in open-top chambers (3.2 m diameter, $3.4 \mathrm{~m}$ height),
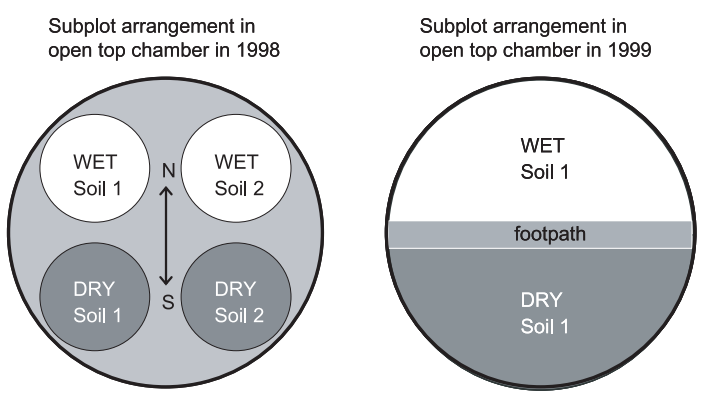

Figure 1. The graph shows the area of an open-top chamber with the subplots for different soil types (soil 1 and soil 2) used in the 1st year and for different water supplies (DRY and WET) used in both years. In the 1st year each open-top chamber was equipped with four lysimeters to grow the plants under the different conditions. In the 2nd year the open-top chambers were operated on an experimental field site.

each equipped with four lysimeters, i.e. large-volume soil containers ( $1 \mathrm{~m}$ diameter, $0.4 \mathrm{~m}$ depth), while in 1999 the plants were sown on an experimental field site of the Federal Agricultural Research Center in Braunschweig, Germany, prior to installation of eight open-top chambers (Fig. 1). In both years, the boundaries of the canopies were formed by shading cloths, which were moved up with the height of the plants to minimize edge effects. Plants were sown in the middle of March at a density of 350 seed $\mathrm{m}^{-2}$ and standard agronomic practice was followed to prevent growth restriction by nutrient limitation and plant diseases. The first node stage occurred at the beginning of May, approximately 35 days after emergence, anthesis was at the beginning of June and grain maturity was reached at the end of July. A detailed description of the crop management has already been given by Manderscheid et al. (2003). Air temperatures in the open-top chambers measured two meters above ground level and averaged from emergence until maturity amounted to $14.0^{\circ} \mathrm{C}$ and $14.2^{\circ} \mathrm{C}$ in the 1 st and 2nd years, respectively, and were $1.6^{\circ} \mathrm{C}$ and $1.1{ }^{\circ} \mathrm{C}$ higher as compared with ambient field conditions.

\subsection{Experimental design and treatment factors}

The experimental design consisted of two $\mathrm{CO}_{2}$ levels and two watering regimes. There were four open-top chamber replicates per $\mathrm{CO}_{2}$ concentration. In the first year, soil type was included as an additional factor and each open-top chamber contained four large-volume soil containers, which were filled with two different soil types and operated with and without water restriction, respectively. In 1999, each open-top chamber was divided into two equally sized subplot areas for the two water treatments (Fig. 1). Lateral water flow inside the chambers was prevented with a plastic foil dug into the ground at $80 \mathrm{~cm}$ depth. Roots did not have access to the groundwater since the water table had a depth of 10 meters.

$\mathrm{CO}_{2}$ enrichment was carried out from emergence until grain maturity, as described previously (Weigel et al., 1992). Atmospheric $\mathrm{CO}_{2}$ concentration was measured in all enriched 
chambers and in at least half of the ambient $\mathrm{CO}_{2}$ chambers. $\mathrm{CO}_{2}$ fumigation was run 24 hours per day.

Rainfall was excluded by the roof of the open-top chamber (Weigel et al., 1992). The well-watered plots were irrigated with tap water and a water meter approximately twice per week according to the demand recorded by soil moisture sensors. Drought stress was started two to three weeks after the first node stage by reducing the amount of irrigation water to approx. $50 \%$ of the well-watered treatment. The two water regimes are designated as WET and DRY.

The two soil types used in 1998 were a cambisol (loamy sand, $\mathrm{pH} 6.5,1.4 \%$ organic matter) and a chernosem (clay loam, $\mathrm{pH} 7.2,4.2 \%$ organic matter). The experimental field site used in 1999 had a cambisol with an Ap horizon of $40 \mathrm{~cm}$ depth and the subsoil consisted of a mixture of gravel and sand. Soil moisture was measured by time domain reflectrometry sensors at one (1998) depth (0.20-0.36 meters) or four (1999) depths (ranging from 0.1-0.9 meters). Plant-available soil water content was calculated as the product of the soil rooting depth and the sensor readings after subtracting the soil water content at the permanent wilting point (Burkart et al., 2004 ) and is given in $\mathrm{mm}$, i.e. $\mathrm{L}$ water per $\mathrm{m}^{2}$ soil area. Rooting depth was assumed to be $0.4 \mathrm{~m}$ (1998) and $0.5 \mathrm{~m}$ (1999), respectively, based on root growth measurements, and the seasonal course of available water in both years has been shown by Burkart et al. (2004). Initially, different soil types were selected in order to have a soil with a low (cambisol) and a high amount of plant-available water (chernosem). However, during the experiment it turned out that there was no great difference in available water between the two soil types. The mean available water averaged over the growth period from the beginning of drought stress until the end of grain filling amounted to $60 \mathrm{~mm}$ (1st year) and $42 \mathrm{~mm}$ (2nd year) for the WET treatment, and to $20 \mathrm{~mm}$ and $19 \mathrm{~mm}$ for the DRY treatment. The individual data for the two soil types (cambisol/chernosem) used in the 1st year were $65 \mathrm{~mm} / 55 \mathrm{~mm}$ and $20 \mathrm{~mm} / 19 \mathrm{~mm}$ for the WET and DRY treatments, respectively.

\subsection{Analysis of plant growth}

During stem elongation, main stem height was measured in 1999 by recording the distance between a reference point on the ground and the stem height at the flag leaf ligula. After cessation of height growth, stem height was measured in both years by recording the distance between the ground and the top of the stem. Readings were taken from five (1998) or ten (1999) plants per open-top chamber and water treatment and the means were used for statistical analysis.

The chlorophyll contents of the 1st (flag leaf), 2nd and 3 rd leaf from the top of the main stem were measured nondestructively during leaf senescence using the MINOLTA SPAD-502 chlorophyll meter. Readings were taken from 10 plants per replicate plot and averaged.

The percentage of photosynthetically active radiation absorbed by the green canopy was measured approximately once per week using a line quantum sensor (Transmission Meter EMS 7, PP Systems, Herts, UK). The measurements included the radiation incident on the canopy $\left(\mathrm{J}_{0}\right)$, reflected by the canopy $\left(\mathrm{J}_{\mathrm{r}}\right)$, and the radiation at the lower limit of the green canopy $\left(\mathrm{J}_{\mathrm{c}}\right)$. \% APAR was calculated using the following equation:

$$
\% \operatorname{APAR}=\left(\mathrm{J}_{0}-\mathrm{J}_{\mathrm{r}}-\mathrm{J}_{\mathrm{c}}\right) / \mathrm{J}_{0} .
$$

The total photosynthetically active radiation absorbed over the whole vegetation period was calculated as the sum of the daily values, which represent the product of incident radiation measured in the open-top chamber and the \%APAR readings. Data from intervening days were obtained by linear interpolation of the \%APAR readings, and numbers for the period between crop emergence and the first measuring date by non-linear interpolation.

In each year, four to five destructive harvests were carried out, starting with the onset of the drought stress approx. 2-3 weeks after the first node stage. Samples of the total aboveground biomass were always taken out of the canopy ( $>20 \mathrm{~cm}$ distance from the edge). At the 1st-5th harvest in 1998, two plants were sampled, and at grain maturity a row section of $1.0 \mathrm{~m}$ length was analyzed. In 1999, the harvested area consisted of a row section of $30 \mathrm{~cm}$ length (1st-5th harvest in open-top chambers) and of $3 \times 50 \mathrm{~cm}$ length (final harvest), respectively. After separation of the green and non-green leaves and stems the projected area of the green leaves and stems was measured with a leaf area meter (Model LI-3100 from LICOR) and used to calculate the green area index. Dry weights of leaves, stems and ears were determined after drying at $95{ }^{\circ} \mathrm{C}$ for $24 \mathrm{~h}$. At maturity, grain yield, ear number, grain number and mean kernel weight were determined after drying and threshing each individual ear. Radiation-use efficiency of aboveground biomass production was calculated as the slope of the regression of aboveground biomass versus cumulative photosynthetically active radiation absorbed by the green canopy starting after the first destructive harvest. Wateruse efficiency was calculated from the values for total aboveground biomass at grain maturity, and the seasonal water consumption is described in Burkart et al. (2004).

\subsection{Statistical analysis}

Data of the different variables and times were subjected to analysis of variance with $\mathrm{CO}_{2}$ and water supply as treatment factors. The least significant difference multiple range test was used to establish significant differences between treatment means $(P<0.05)$. Data from the two soil types used in 1998 were pooled since the $\mathrm{CO}_{2}$ effect on all variables measured did not significantly interact with soil type. All calculations were performed with the STSC Statgraphics software.

\section{RESULTS AND DISCUSSION}

The seasonal means of the atmospheric $\mathrm{CO}_{2}$ concentration in the ambient and high $\mathrm{CO}_{2}$ chambers amounted to $381 \mathrm{ppm}$ and $671 \mathrm{ppm}$ in 1998, and to 409 and $684 \mathrm{ppm}$ in 1999, respectively. Thus, averaged over both years atmospheric $\mathrm{CO}_{2}$ 


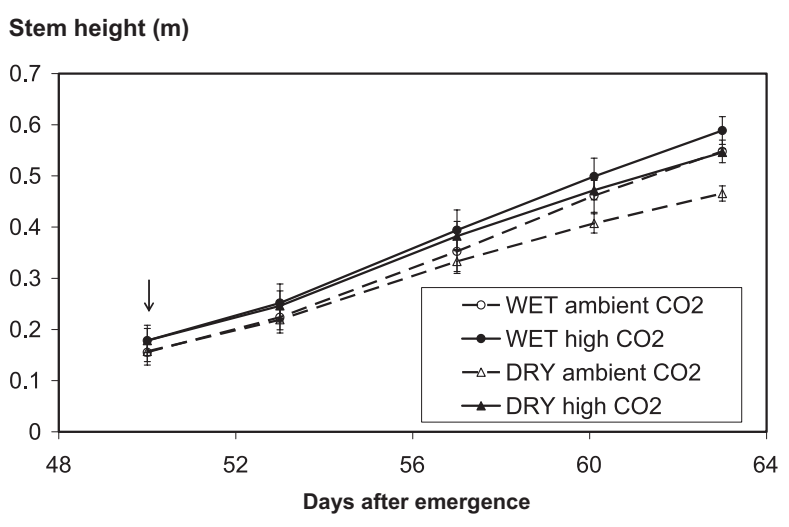

Figure 2. Effects of two atmospheric $\mathrm{CO}_{2}$ concentrations (ambient and high $\mathrm{CO}_{2}$ ) and two watering regimes (WET and DRY) on stem height of wheat plants grown in 1999. Water shortage reduces stem height more under ambient than high $\mathrm{CO}_{2}$ concentration. Values represent means \pm standard error $(3 \leq n \leq 4)$. The arrow indicates the start of water shortage.

was elevated by approx. 280 ppm above ambient in the high $\mathrm{CO}_{2}$ treatment. Drought stress did not affect the time to anthesis, but the date of grain maturity was reached one week earlier for plants grown under limited rather than sufficient water supply.

\subsection{Canopy growth and senescence}

\subsubsection{Canopy expansion}

Treatment effects on canopy expansion were studied by recording stem height when water addition to DRY plots was reduced. Figure 2 shows the results for the 2nd year. Stem height was significantly decreased by drought after 63 days after emergence under ambient $\mathrm{CO}_{2}$ but not in the high $\mathrm{CO}_{2}$ treatment. This corresponds to the results of Clifford et al. (1993), who found that the decline in the leaf extension rate under drought was delayed by $\mathrm{CO}_{2}$ enrichment. After cessation of stem growth, stem height was found in both years to be more increased by $\mathrm{CO}_{2}$ elevation in DRY plots than in WET plots (Tab. I).

\subsubsection{Temporal changes in leaf chlorophyll content}

Drought stress resulted in an accelerated chlorophyll breakdown starting in the lower leaves, as shown for 1999 in Figure 3. $\mathrm{CO}_{2}$ enrichment did not modify this effect, while under WET conditions high $\mathrm{CO}_{2}$ concentrations also accelerated leaf senescence, with the effect being greatest for the lowest leaf. This is confirmed by a significant interaction effect $(P<0.05)$ of $\mathrm{CO}_{2}$ and water supply on the 3rd and 2 nd leaf found for the last four and two measuring dates, respectively. The findings of 1998 were similar (data not shown).

The $\mathrm{CO}_{2}$-related decrease in leaf chlorophyll content under WET conditions corresponds to previous findings (Miller
Table I. Effects of $\mathrm{CO}_{2}$ enrichment (ambient, high $\mathrm{CO}_{2}$ ) and water supply (WET/DRY) on stem height measured ca. 10 days after anthesis in two years. Values represent means \pm standard error $(n=7$ for data of 1998, readings from two soil types were combined; $\mathrm{n}=$ 4 for data of 1999). Values within a row followed by different letters are significantly different at the $5 \%$ level using the least significant difference multiple range test. WET: sufficient watering; DRY: 50\% of the WET level starting after stem elongation.

\begin{tabular}{ccccc}
\hline \multirow{2}{*}{ year } & \multirow{2}{*}{ watering } & \multicolumn{2}{c}{ stem height $(\mathrm{m})$} & \multirow{2}{*}{$\% \mathrm{CO}_{2}$ effect } \\
\cline { 3 - 4 } & & ambient $\mathrm{CO}_{2}$ & high $\mathrm{CO}_{2}$ & \\
\hline \multirow{2}{*}{1998} & WET & $0.85 \pm 0.03$ & $0.92 \pm 0.02$ & +7.9 \\
& DRY & $0.60 \pm 0.02 a$ & $0.80 \pm 0.03 b$ & +33.4 \\
1999 & WET & $0.88 \pm 0.05$ & $0.95 \pm 0.05$ & +7.5 \\
& DRY & $0.66 \pm 0.05 a$ & $0.83 \pm 0.06 b$ & +27.1 \\
\hline
\end{tabular}

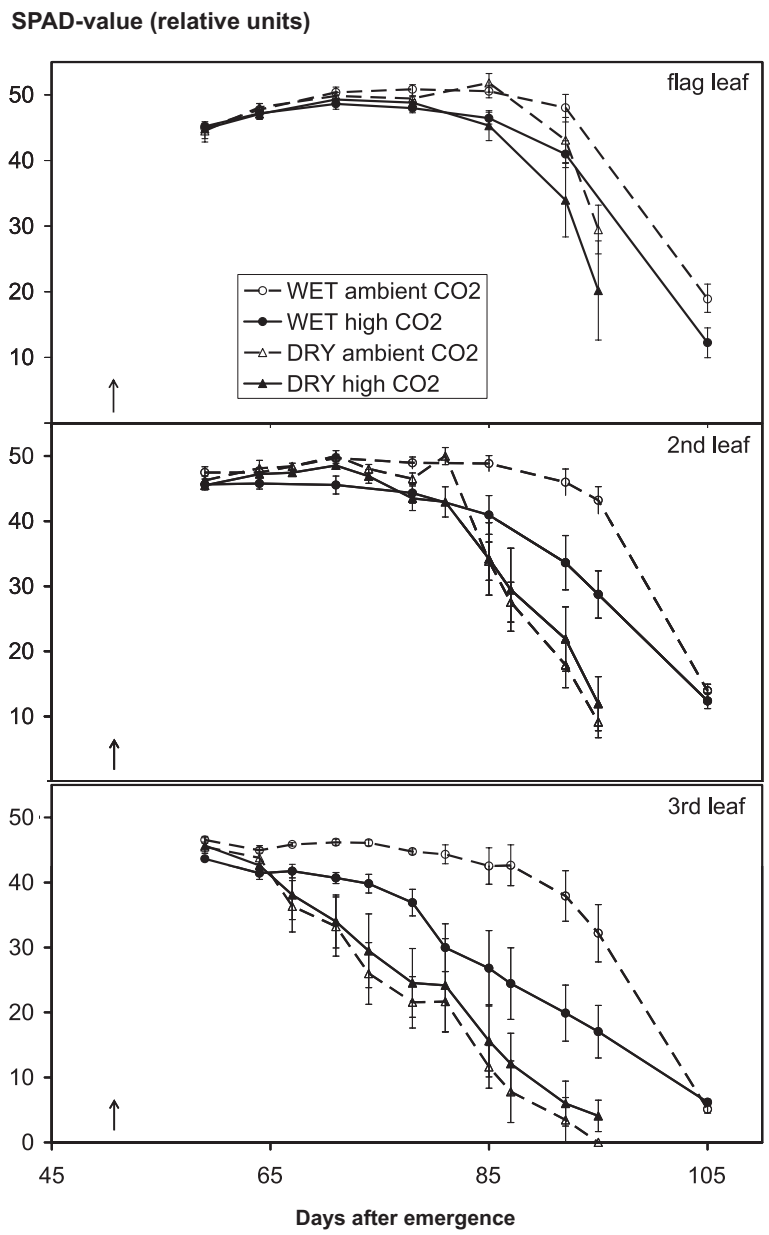

Figure 3. Effects of two atmospheric $\mathrm{CO}_{2}$ concentrations (ambient and high $\mathrm{CO}_{2}$ ) and two watering regimes (WET and DRY) on chlorophyll content of the three uppermost leaves of the stem of wheat plants grown on a field site in 1999. Chlorophyll was measured nondestructively using the SPAD-502 chlorophyll meter. Water shortage results in an accelerated decline in chlorophyll content, especially in older leaves, and $\mathrm{CO}_{2}$ enrichment decreases chlorophyll content under WET conditions. Values represent means \pm standard error $(n=$ 4). The arrow indicates the start of water shortage. 
Green area index (m2 m-2)

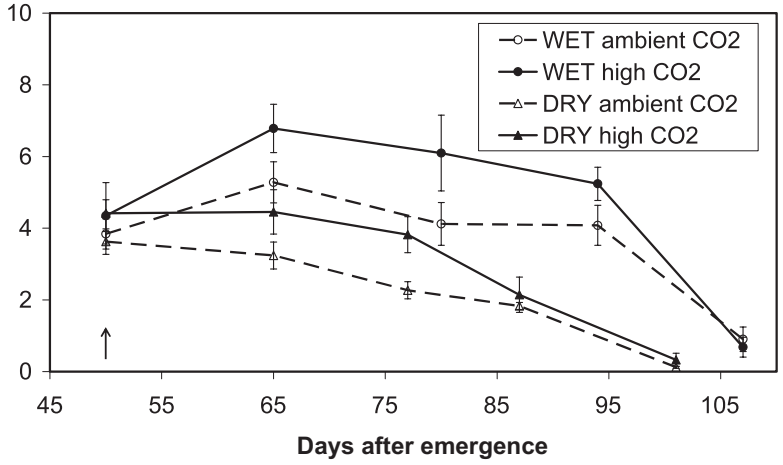

Figure 4. Effects of two atmospheric $\mathrm{CO}_{2}$ concentrations (ambient and high $\mathrm{CO}_{2}$ ) and two watering regimes (WET and DRY) on the green area index of wheat plants grown on a field site in 1999. Water shortage reduces the green area index and $\mathrm{CO}_{2}$ enrichment increases the green area index under DRY conditions. Values represent means \pm standard error $(n=4)$. The arrow indicates the start of water shortage.

et al., 1997; Ommen et al., 1999) and indicates that $\mathrm{CO}_{2}$ acclimation occurred under WET conditions.

\subsubsection{Seasonal variation in the green area index}

Figure 4 shows the seasonal course of the green area index in 1999. The start of the drought stress prevented the continuation of the increase in the green area index, as visible in the WET treatment, and accelerated the senescence of the canopy. $\mathrm{CO}_{2}$ enrichment did not significantly increase the green area index under WET conditions, but it did under DRY conditions at the third harvest $(P=0.03)$. In 1998, the green area index was not affected by $\mathrm{CO}_{2}$ enrichment. The green area index consisted of the green area of leaves and of stems. A separate analysis of these two fractions for 1998 yielded no $\mathrm{CO}_{2}$ effect on the green leaf area, but stem area was significantly increased $(P<0.05)$ at the 2 nd harvest in DRY plots and at the 3rd and 4th harvest in WET plots, respectively. This corresponded to the findings for 1999, when green stem area was also found to be significantly increased by $\mathrm{CO}_{2}$ enrichment at one (WET) or two (DRY) harvest dates. Moreover, there was a slightly significant $\mathrm{CO}_{2}$-related stimulation in green leaf area of DRY plots at the 3rd harvest $(P=0.06)$. Thus, under drought stress $\mathrm{CO}_{2}$ enrichment increased green stem area in both years; however, effects on the total green area index were only visible in the second year.

Drought stress is known to affect the rise in the green area index and to accelerate the decline (Foulkes et al., 2001). This is confirmed by our findings for the ambient $\mathrm{CO}_{2}$ conditions. However, $\mathrm{CO}_{2}$ elevation increased the green area index under drought only in 1999, since leaf area, which is the most important for the green area index, was only affected in the second year. Stimulation of leaf area of wheat under drought by high $\mathrm{CO}_{2}$ concentrations has also been found in previous studies (Pinter et al., 1996; Samarakoon et al., 1995).

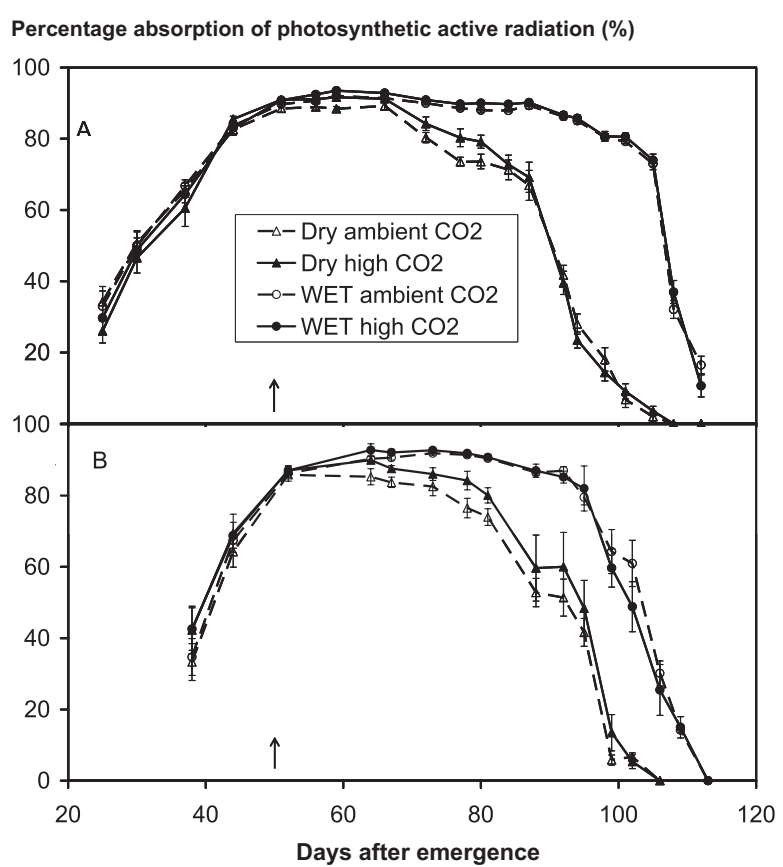

Figure 5. Effects of two atmospheric $\mathrm{CO}_{2}$ concentrations (ambient and high $\mathrm{CO}_{2}$ ) and two watering regimes (WET and DRY) on percentage absorption of photosynthetically active radiation of the green canopy of wheat plants grown in lysimeters in 1998 (A) and on a field site in 1999 (B). Water shortage reduces percentage radiation absorption in the second half of the vegetation period and this effect is mitigated by $\mathrm{CO}_{2}$ enrichment, especially in the second year. Values represent means \pm standard error ( $n=8$ and 4, in 1998 and 1999, respectively). The arrow indicates the start of water shortage.

\subsubsection{Radiation absorption by the green canopy}

Two-way analysis of variance yielded a significant drought effect on APAR\% starting at 56 and 64 days after emergence, respectively, in 1998 and 1999, while significant $\mathrm{CO}_{2}$ responses were first detectable at 51 and 64 days after emergence (Fig. 5). The positive $\mathrm{CO}_{2}$ effect persisted until ca. 80 days after emergence in both seasons and the size of the effect was greater under DRY than under WET conditions.

The fraction of photosynthetically active radiation absorbed from crop emergence until the first measuring date of \%APAR was small $(<5 \%)$ as compared with the radiation absorbed over the whole season. Thus, even if there was an undetected $\mathrm{CO}_{2}$ effect on radiation absorption in the early beginning, this would not greatly affect the radiation absorption for the whole season. In the first year, radiation absorption was influenced by water supply, while the $\mathrm{CO}_{2}$ treatment had no effect (Tab. II). However, in the second year radiation absorption was significantly increased by $\mathrm{CO}_{2}$ enrichment under drought. Consequently, radiation absorption was reduced by $18 \%$ in DRY plots as compared with WET plots for both $\mathrm{CO}_{2}$ treatment levels in 1998. However, in 1999 the reduction in radiation absorption by drought amounted to $23 \%$ and $16 \%$ for the ambient and high $\mathrm{CO}_{2}$ treatments, respectively. 
Table II. Sum of seasonal absorption of photosynthetically active radiation of wheat canopies for two years and different water (WET/DRY) and $\mathrm{CO}_{2}$ regimes (ambient/high). Values represent means \pm standard error $(n=8$ in 1998 , readings from two soil types were combined; $n=4$ in 1999). Values within a row followed by different letters are significantly different at the $5 \%$ level using the least significant difference multiple range test. PAR: photosynthetically active radiation; WET: sufficient watering; DRY: 50\% of the WET level starting after stem elongation.

\begin{tabular}{llccc}
\hline \multirow{2}{*}{ year } & watering & \multicolumn{2}{c}{ PAR absorption $\left(\mathrm{mol} \mathrm{m}^{-2}\right)$} & \multirow{2}{*}{$\mathrm{CO}_{2}$ effect } \\
\cline { 3 - 4 } & & $1433 \pm 11$ & $1430 \pm 9$ & $-0.2 \%$ \\
\hline 1998 & WET & $1166 \pm 20$ & $1171 \pm 11$ & $+0.4 \%$ \\
& DRY & $-18.6 \%$ & $-18.1 \%$ & \\
& $\%$ drought effect & $\mathrm{CO}_{2}$ & high $\mathrm{CO}_{2}$ & \\
1999 & WET & $1668 \pm 24$ & $1694 \pm 18$ & $+1.6 \%$ \\
& DRY & $1290 \pm 29 a$ & $1419 \pm 10 b$ & $+10.0 \%$ \\
& $\%$ drought effect & $-22.7 \%$ & $-16.2 \%$ & \\
\hline
\end{tabular}

Measurements of light absorption by the green canopy confirmed the $\mathrm{CO}_{2}$ effect on the green area index under drought in the 2nd year. The absence (Pinter et al., 1994) and the presence of a positive $\mathrm{CO}_{2}$ response of radiation absorption (Clifford et al., 1993) under drought have also been found in previous studies.

As outlined in our hypotheses the positive $\mathrm{CO}_{2}$ effect on the green area index and radiation absorption can be attributed to two mechanisms, (i) a decrease in stomatal conductance, and consequently in canopy water flux, and (ii) the exploitation of additional water resources by increasing root growth (Polley, 2002).

Appropriate analyses were done during our experiment, and regarding the first mechanism it was found that under WET conditions canopy water flux was decreased by $\mathrm{CO}_{2}$ enrichment (ca. 20\%) and also seasonal water use by $14 \%$ (Burkart et al., 2004). However, drought stress was initiated shortly after canopy closure and before this stage soil water content is also strongly influenced by evaporation. Therefore, it can be assumed that the effect of the $\mathrm{CO}_{2}$-related decrease in canopy conductance on plant-available soil water was still small at the start of the drought stress treatment. This is confirmed by the finding that $\mathrm{CO}_{2}$ enrichment retarded the drought effect on stem expansion only for a few days and that soil water content was not significantly different between the two $\mathrm{CO}_{2}$ treatment levels (Burkart et al., 2004).

In the 1st year root growth was limited in the lysimeters to a soil depth of 0.4 meters. Consequently, the lack of an increase in radiation absorption by $\mathrm{CO}_{2}$ enrichment in 1998 can be ascribed to the restriction of root growth. Similarly, the small $\mathrm{CO}_{2}$ response of the leaf area index under drought and the lack of an increase in radiation absorption found in field studies under arid conditions (Pinter et al., 1994, 1996) could also be explained by this mechanism since these plants could only exploit the irrigation water. In the 2 nd year of our experiment, when plants were grown in the field without restriction to root growth, it was observed that $\mathrm{CO}_{2}$ enrichment stimulated root
Table III. Radiation-use efficiency of aboveground biomass production in $\mathrm{g}$ dry weight per mol photons of wheat canopies for two years and different water (WET/DRY) and $\mathrm{CO}_{2}$ regimes (ambient/high). Values represent means \pm standard error $(\mathrm{n}=8$ in 1998, readings from two soil types were combined; $n=4$ in 1999). Values within a row followed by different letters are significantly different at the $5 \%$ level using the least significant difference multiple range test. RUE: radiation-use efficiency.

\begin{tabular}{|c|c|c|c|c|}
\hline \multirow{2}{*}{ year } & \multirow{2}{*}{ watering } & \multicolumn{2}{|c|}{ RUE $\left(\mathrm{g} \mathrm{mol}^{-1}\right)$} & \multirow{2}{*}{$\% \mathrm{CO}_{2}$ effect } \\
\hline & & ambient $\mathrm{CO}_{2}$ & high $\mathrm{CO}_{2}$ & \\
\hline \multirow[t]{3}{*}{1998} & WET & $1.42 \pm 0.14$ & $1.78 \pm 0.11$ & $+25 \%$ \\
\hline & DRY & $0.961 \pm 0.21 a$ & $1.61 \pm 0.15 b$ & $+68 \%$ \\
\hline & $\%$ drought effect & $-32 \%$ & $-10 \%$ & \\
\hline \multirow[t]{3}{*}{1999} & WET & $0.951 \pm 0.07 a$ & $1.32 \pm 0.11 b$ & $+39 \%$ \\
\hline & DRY & $0.613 \pm 0.01 a$ & $0.924 \pm 0.04 b$ & $+51 \%$ \\
\hline & $\%$ drought effect & $-36 \%$ & $-30 \%$ & \\
\hline
\end{tabular}

growth under DRY conditions, especially in the deeper soil layers (Burkart et al., 2004). This enabled the plants to exploit additional soil water resources and seems to be responsible for the positive $\mathrm{CO}_{2}$ effect on the green area index and radiation absorption under drought in 1999.

\subsection{Radiation-use efficiency}

For the small plot size (ca. $1 \mathrm{~m}^{2}$ ) used in 1998, the calculated radiation-use efficiency was ca. 50\% higher than the respective number found for 1999 with a plot size of ca. $3 \mathrm{~m}^{2}$ (Tab. III). Drought stress decreased radiation-use efficiency under ambient $\mathrm{CO}_{2}$ by approx. one-third. This was highly significant in $1999(P=0.003) . \mathrm{CO}_{2}$ enrichment increased radiation-use efficiency by $25 \%$ and $39 \%$ in the 1 st and 2 nd year, respectively. Although there was no significant interaction effect of $\mathrm{CO}_{2}$ and water supply on radiation-use efficiency, the $\mathrm{CO}_{2}$-related stimulation was always higher under DRY $(\geq 51 \%)$ than WET conditions $(\leq 39 \%)$.

The higher values of radiation-use efficiency obtained in 1998 may be explained by the small plot size used in this year, which resulted in a great part of the lateral radiation absorbed by the canopy not being included in the calculation. Drought stress decreased radiation-use efficiency, which is in line with previous findings (Foulkes et al., 2001; Jamieson et al., 1995). Averaged over both years, $\mathrm{CO}_{2}$ enrichment increased radiation-use efficiency in our study by $32 \%$ and $59 \%$ under WET and DRY conditions, respectively. This result confirms the hypothesis that the $\mathrm{CO}_{2}$ response of radiation-use efficiency is higher under drought than well-watered conditions, as found by Clifford et al. (1993), but it is in contrast to the findings of Pinter et al. (1996), who observed a similar stimulation of radiation-use efficiency of cotton by free air $\mathrm{CO}_{2}$ enrichment both in the wet and dry treatments.

According to our hypotheses a decrease in stomatal conductance is a prerequisite for a higher $\mathrm{CO}_{2}$ response of radiationuse efficiency under DRY than WET conditions. Drought effects on stomatal conductance have been confirmed in the 
Table IV. $P$-values of the two-way analysis of variance for the effects of water (WET/DRY) and $\mathrm{CO}_{2}$ supply (ambient/high) on growth variables of wheat at maturity in 1998 and 1999, respectively, and the means for the different treatments and years. Values within a row followed by different letters are significantly different at the $5 \%$ level using the least significant difference multiple range test. $P$-values are indicated by: $(*)$ $P<0.10, * P<0.05$, ** $P<0.01$ and $* * * P<0.001$. WET: sufficient watering; DRY: $50 \%$ of the WET level starting after stem elongation.

\begin{tabular}{|c|c|c|c|c|c|c|c|}
\hline \multirow{2}{*}{ variable } & \multicolumn{3}{|c|}{$P$-values } & \multirow{2}{*}{ water level } & \multicolumn{2}{|c|}{$\mathrm{CO}_{2}$ level } & \multirow{2}{*}{$\mathrm{CO}_{2} \%$ effect } \\
\hline & water & $\mathrm{CO}_{2}$ & $\mathrm{w} * \mathrm{C}$ & & amb. & high & \\
\hline \multicolumn{8}{|c|}{1998} \\
\hline \multirow[t]{2}{*}{ biomass $\left(\mathrm{g} \mathrm{m}^{-2}\right)$} & $* * *$ & $* * *$ & $*$ & WET & 1917 & 2081 & +8.6 \\
\hline & & & & DRY & $1164 a$ & $1667 b$ & +43.2 \\
\hline \multirow[t]{2}{*}{ ear number $\left(\mathrm{m}^{-2}\right)$} & $* * *$ & $* *$ & - & WET & $781 a$ & $913 b$ & +16.9 \\
\hline & & & & DRY & 522 & 610 & +16.9 \\
\hline \multirow[t]{2}{*}{ grain number per ear } & $* * *$ & - & $*$ & WET & 33.8 & 32.3 & -4.4 \\
\hline & & & & DRY & 24.4 & 29.0 & +18.9 \\
\hline \multirow[t]{2}{*}{ mean grain weight (mg) } & $* * *$ & - & $(*)$ & WET & 32.7 & 30.3 & -7.3 \\
\hline & & & & DRY & 38.4 & 39.6 & +3.1 \\
\hline \multirow[t]{2}{*}{ grain yield $\left(\mathrm{g} \mathrm{m}^{-2}\right)$} & $* * *$ & $* * *$ & $* *$ & WET & 854 & 884 & +3.5 \\
\hline & & & & DRY & $476 a$ & $687 b$ & +44.3 \\
\hline \multicolumn{8}{|c|}{1999} \\
\hline \multirow[t]{2}{*}{ biomass $\left(\mathrm{g} \mathrm{m}^{-2}\right)$} & $* * *$ & $* *$ & - & WET & 1842 & 2068 & +12.2 \\
\hline & & & & DRY & $960 a$ & $1392 b$ & +45.0 \\
\hline \multirow[t]{2}{*}{ ear number $\left(\mathrm{m}^{-2}\right)$} & $* * *$ & $*$ & - & WET & 588 & 659 & +12.1 \\
\hline & & & & DRY & $411 a$ & $472 b$ & +14.8 \\
\hline \multirow[t]{2}{*}{ grain number per ear } & $* *$ & $(*)$ & $*$ & WET & 44.9 & 44.1 & -1.8 \\
\hline & & & & DRY & $33.9 a$ & $41.2 b$ & +21.5 \\
\hline \multirow[t]{2}{*}{ mean grain weight (mg) } & - & - & - & WET & 34.4 & 34.8 & +1.2 \\
\hline & & & & DRY & 31.5 & 34.0 & +7.9 \\
\hline \multirow[t]{2}{*}{ grain yield $\left(\mathrm{g} \mathrm{m}^{-2}\right)$} & $* * *$ & $* *$ & - & WET & 901 & 1014 & +12.5 \\
\hline & & & & DRY & $434 a$ & $654 b$ & +50.7 \\
\hline
\end{tabular}

study of Clifford et al. (1993) and in our experiment (Burkart et al., 2004). It can be speculated that in the free air carbon dioxide enrichment study cited above (Pinter et al., 1996), with an early start of the water deficit, plants adjusted to the drought stress primarily by reducing the transpiring leaf area, and consequently the radiation absorption and not the stomatal conductance of the remaining leaves. This is supported by field studies showing that radiation-use efficiency is hardly affected by early drought stress (Stone et al., 2001; O'Connell et al., 2004) and that the ratio of actual to potential evapotranspiration is independent of the water supply (Brisson and Casals, 2005).

\subsection{Final biomass and grain yield}

In both years, biomass and grain yield were decreased by drought and increased by $\mathrm{CO}_{2}$ enrichment (Tab. IV). In 1998, there was a significant interaction effect of $\mathrm{CO}_{2}$ and water supply on biomass, grain number per ear and grain yield, based on a higher $\mathrm{CO}_{2}$ response under drought than under sufficient watering. Although the data of the 2 nd year yielded only a significant $\mathrm{CO}_{2} \times$ water interaction effect on grain number per ear, the observed relative $\mathrm{CO}_{2}$ effects on growth and yield variables were quite similar to the findings of the 1st year. Thus, averaged over both years $\mathrm{CO}_{2}$ enrichment increased biomass and grain yield under WET conditions by $\leq 10 \%$ and under DRY conditions by $\geq 44 \%$. The $\mathrm{CO}_{2}$-related stimulation of grain yield was due to a significant increase in ear number $(+12 \%$ to $+17 \%)$ in both watering regimes, and the $\mathrm{CO}_{2} \times$ water interaction could be mainly attributed to an increase in grain number per ear (+20\%) under drought stress. In addition, mean grain weight was slightly increased by $\mathrm{CO}_{2}$ enrichment under DRY $(+5 \%)$, but not under WET conditions, as indicated by the slightly significant interaction of $\mathrm{CO}_{2}$ and water supply found in 1998.

Enhancement of the $\mathrm{CO}_{2}$ effect on growth under drought has been reported by several authors (Chaudhuri et al., 1990; Gifford, 1979; Kang et al., 2002; Pinter et al., 1996). In field experiments the $\mathrm{CO}_{2}$ response of grain yield under drought ranged from $+20 \%$ (Pinter et al., 1996) to $+50 \%$, as observed by Chaudhuri et al. (1990) and also in the present project. The severity of the drought stress as indicated by the reduction in grain yield under ambient $\mathrm{CO}_{2}$ concentration also varied from $-30 \%$ (Pinter et al., 1996) to $-50 \%$ (Chaudhuri et al., 1990), similarly to the presented study. Thus, the relative $\mathrm{CO}_{2}$ 
Table V. Water-use efficiency of aboveground biomass production ( $\mathrm{g}$ dry weight per $\mathrm{kg}$ water) of wheat canopies grown for two years under different water (WET/DRY) and $\mathrm{CO}_{2}$ regimes (ambient/high). Values represent means \pm standard error ( $\mathrm{n}=8$ in 1998, readings from two soil types were combined; $n=4$ in 1999). Values within a row followed by different letters are significantly different at the $5 \%$ level using the least significant difference multiple range test. WET: sufficient watering; DRY: $50 \%$ of the WET level starting after stem elongation; WUE: water-use efficiency of aboveground biomass production.

\begin{tabular}{ccccc}
\hline \multirow{2}{*}{ year } & watering & \multicolumn{2}{c}{ WUE $\left(\mathrm{g} \mathrm{kg}^{-1}\right)$} & \multirow{2}{*}{$\% \mathrm{CO}_{2}$ effect } \\
\cline { 3 - 4 } & & ambient $\mathrm{CO}_{2}$ & high $\mathrm{CO}_{2}$ & \\
\hline \multirow{2}{*}{1998} & WET & $4.65 \pm 0.13 a$ & $5.87 \pm 0.19 b$ & $+26 \%$ \\
& DRY & $5.15 \pm 0.34 a$ & $7.38 \pm 0.33 b$ & $+43 \%$ \\
\multirow{2}{*}{1999} & WET & $4.08 \pm 0.23$ & $4.60 \pm 0.28$ & $+13 \%$ \\
& DRY & $4.10 \pm 0.22 a$ & $5.82 \pm 0.21 b$ & $+42 \%$ \\
\hline
\end{tabular}

response of plant growth under drought seems to increase with the degree of water shortage, which corresponds to the finding that percentage stimulation of photosynthesis by $\mathrm{CO}_{2}$ elevation rises when water availability is reduced and stomatal conductance decreases (Andre and Du Cloux, 1993).

In the present study reduction in water supply was initiated shortly after the first node stage. This resulted in a decrease in ear number by ca. $30 \%$ in both seasons and for both $\mathrm{CO}_{2}$ treatment levels. The stronger $\mathrm{CO}_{2}$ response of leaf photosynthesis under drought as compared with well-watered conditions may have been responsible for the $\mathrm{CO}_{2} \times$ water interaction effect on grain number per ear observed in this study for both years and also by Chaudhuri et al. (1990).

\subsection{Water-use efficiency}

There was a significant interaction effect between $\mathrm{CO}_{2}$ and water supply on water-use efficiency in 1999, and in 1998 the respective $P$-value was slightly above the level of significance $(P=0.06) . \mathrm{CO}_{2}$ enrichment and reduction in water supply both resulted in an increase in water-use efficiency (Tab. V). The results clearly indicated that the $\mathrm{CO}_{2}$-related stimulation of water-use efficiency was greater under limited $(+43 \%)$ than sufficient water supply $(+20 \%)$. Similar results have been obtained in other field (Chaudhuri et al., 1990; Hunsaker et al., 1996) and controlled environment studies (Gifford, 1979). They support the hypothesis that the relative stimulation of photosynthesis by $\mathrm{CO}_{2}$ elevation increases with the severity of drought stress (Andre and Du Cloux, 1993; Kang et al., 2002).

\section{CONCLUSION}

It is concluded that in this open-top chamber study $\mathrm{CO}_{2}$ enrichment produces a greater relative stimulation in plant growth under DRY than WET conditions. The higher $\mathrm{CO}_{2}$ response under limited water supply is due to an increase in radiation absorption by the green canopy and in radiation-use efficiency. A prerequisite for the stimulation of radiation absorption by high $\mathrm{CO}_{2}$ is the availability of water in deeper soil layers which can be exploited by increasing root growth. A prerequisite for a strong stimulation of radiation-use efficiency is a drought effect on stomatal conductance. Moreover, it was shown that halving the water supply after the first node stage resulted in a halving of grain yield. However, under elevated atmospheric $\mathrm{CO}_{2}$ concentrations, drought stress decreased grain yield by only one-quarter.

There are several aspects which have to be considered for transfer of our findings obtained within open-top chambers to field conditions. The $\mathrm{CO}_{2}$-related reduction in canopy transpiration may be smaller in the field because of the lower wind speed as compared with open-top chambers, which results in a poorer aerodynamic coupling of the canopy to the atmosphere. Another point is the size of the water resources in deeper soil layers. In our experiment in 1999, when $\mathrm{CO}_{2}$ enrichment increased seasonal radiation absorption under drought, the deeper soil layers $(>40 \mathrm{~cm}$ ) had a low water-holding capacity (Burkart et al., 2004). Field sites with a higher waterholding capacity in deeper soil layers might show a greater $\mathrm{CO}_{2}$ effect on radiation absorption under drought than found in this study.

In any case, our findings imply that negative effects on wheat yield resulting from increased water shortage, as predicted from global climate models for the future, may be mitigated by the higher $\mathrm{CO}_{2}$ concentration and yield may be decreased to a lesser extent if all other environmental conditions remain the same.

Acknowledgements: We are grateful to Peter Braunisch, Martina Heuer, Britta Müller, Anke Mundt, Peter Seehawer, Ralf-Dietrich Staudte and Wilfried Woyde for technical support. This research was part of the IMPETUS-project funded by the EC (ENV4-CT97-0496). We are also grateful for financial support from the Federal Ministry of Agriculture, Food and Consumer Protection.

\section{REFERENCES}

Andre M., Du Cloux H. (1993) Interaction of $\mathrm{CO}_{2}$ enrichment and water limitations on photosynthesis and water efficiency in wheat, Plant Physiol. Bioch. 31, 103-112.

Baker J.T., Allen L.H., Boote K.J., Pickering N.B. (1997) Rice responses to drought under carbon dioxide enrichment. 1. Growth and yield, Global Change Biol. 3, 119-128.

Brisson N., Casals M.L. (2005) Leaf dynamics and crop water status throughout the growing cycle of durum wheat crops grown in two contrasted water budget conditions, Agron. Sustain. Dev. 25, 151158.

Burkart S., Manderscheid R., Weigel H.J. (2004) Interactive effects of elevated atmospheric $\mathrm{CO}_{2}$-concentrations and plant available soil water content on canopy evapotranspiration and conductance of spring wheat, Eur. J. Agron. 21, 401-417.

Chaudhuri U.N., Kirkham M.B., Kanemasu E.T. (1990) Carbon dioxide and water level effects on yield and water use of winter wheat, Agron. J. 82, 637-641.

Clifford S.C., Stronach I.M., Mohamed A.D., Azamali S.N., Crout N.M.J. (1993) The effects of elevated atmospheric carbon dioxide and water stress on light interception, dry matter production and yield in 
stands of groundnut (Arachis hypogaea L.), J. Exp. Bot. 44, 17631770 .

Foulkes M.J., Scott R.K., Sylvester-Bradley R. (2001) The ability of wheat cultivars to withstand drought in UK conditions: formation of grain yield, J. Agr. Sci. 38, 153-169.

Gifford R.M. (1979) Growth and yield of $\mathrm{CO}_{2}$-enriched wheat under water-limited conditions, Aust. J. Plant Physiol. 6, 367-378.

Gregory J.M., Mitchell J.F.B., Brady A.J. (2003) Summer drought in northern midlatitudes in a time-dependent $\mathrm{CO}_{2}$ climate experiment, J. Climate 10, 662-686.

Houghton J.T., Ding Y., Griggs D.J., Noguer M., van der Linden P.J., Dai X., Maskell K., Johnson C.A. (2001) Climate Change 2001: The scientific basis. Intergovernmental Panel on Climate Change 2001, Cambridge University Press, Cambridge.

Hunsaker D.J., Kimball B.A., Pinter P.J., Lamorte R.L., Wall G.W. (1996) Carbon dioxide enrichment and irrigation effects on wheat evapotranspiration and water use efficiency, T. ASAE 39, 1345-1355.

Idso K.E., Idso S.B. (1994) Plant responses to atmospheric $\mathrm{CO}_{2}$ enrichment in the face of environmental constraints - A review of the past 10 years research, Agr. Forest Meteorol. 69, 153-203.

Jamieson P.D., Martin R.J., Francis G.S., Wilson D.R. (1995) Drought effects on biomass production and radiation-use efficiency in barley, Field Crop. Res. 43, 77-86.

Jamieson P.D., Porter J.R., Goudriaan J., Ritchie J.T., Vankeulen H., Stol W. (1998) A comparison of the models AFRCWHEAT2, CERESwheat, Sirius, SUCROS2 and SWHEAT with measurements from wheat grown under drought, Field Crop. Res. 55, 23-44.

Kang S., Zhang F., Hu X., Zhang J. (2002) Benefits of $\mathrm{CO}_{2}$ enrichment on crop plants are modified by soil water, Plant Soil 239, 59-77.

Kimball B.A., Pinter P.J., Garcia R.L., Lamorte R.L., Wall G.W., Hunsaker D.J., Wechsung G., Wechsung F., Kartschall T. (1995) Productivity and water use of wheat under free-air $\mathrm{CO}_{2}$ enrichment, Global Change Biol. 1, 429-442.

Manderscheid R., Burkart S., Bramm A., Weigel H.J. (2003) Effect of $\mathrm{CO}_{2}$ enrichment on growth and daily radiation use efficiency of wheat in relation to temperature and growth stage, Eur. J. Agron. $19,41-425$.

Miller A., Tsai C.H., Hemphill D., Endres M., Rodermel S., Spalding M. (1997) Elevated $\mathrm{CO}_{2}$ effects during leaf ontogeny - A new perspective on acclimation, Plant Physiol. 115, 1195-1200.
Mitchell R.A.C., Mitchell V.J., Lawlor D.W. (2001) Response of wheat canopy $\mathrm{CO}_{2}$ and water gas-exchange to soil water content under ambient and elevated $\mathrm{CO}_{2}$, Global Change Biol. 7, 599-611.

O’Connell M.G., O’Leary G.J., Whitfield D.M., Connor D.J. (2004) Interception of photosynthetically active radiation and radiation-use efficiency of wheat, field pea and mustard in a semi-arid environment, Field Crop. Res. 85, 111-124.

Ommen O.E., Donnelly A., Vanhoutvin S., van Oijen M., Manderscheid R. (1999) Chlorophyll content of spring wheat flag leaves grown under elevated $\mathrm{CO}_{2}$ concentrations and other environmental stresses within the ESPACE-wheat project, Eur. J. Agron. 10, 197-20.

Pinter P.J., Kimball B.A., Mauney J.R., Hendrey G.R., Lewin K.F., Nagy J. (1994) Effects of free-air carbon dioxide enrichment on PAR absorption and conversion efficiency by cotton, Agr. Forest Meteorol. 70, 209-230.

Pinter P.J., Kimball B.A., Garcia R.L., Wall G.W., Hunsaker D.J., Lamorte R.L. (1996) Free-air $\mathrm{CO}_{2}$ enrichment: Responses of cotton and wheat crops, in: Koch G.W., Mooney H.A. (Eds.), Carbon Dioxide and Terrestrial Ecosystems, Academic Press, San Diego, pp. 215-247.

Polley H.W. (2002) Implications of atmospheric and climatic change for crop yield and water use efficiency, Crop Sci. 42, 131-140.

Rogers H.H., Cure J.D., Smith J.M. (1986) Soybean growth and yield response to elevated carbon dioxide, Agr. Ecosyst. Environ. 16, 113128.

Sadras V.O., Milroy S.P. (1996) Soil-water thresholds for the responses of leaf expansion and gas exchange: A review, Field Crop. Res. 47, 253-266.

Samarakoon A.B., Muller W.J., Gifford R.M. (1995) Transpiration and leaf area under elevated $\mathrm{CO}_{2}$ : effects of soil water status and genotype in wheat, Aust. J. Plant Physiol. 22, 33-44.

Sionit N., Hellmers H., Strain B.R. (1980) Growth and yield of wheat under $\mathrm{CO}_{2}$ enrichment and water stress, Crop. Sci. 20, 687-690.

Stone P.J., Wilson D.R., Reid J.B., Gillespie R.N. (2001) Water deficit effects on sweet corn. I. Water use, radiation use efficiency, growth, and yield, Aust. J. Agr. Res. 52, 103-113.

Weigel H.J., Mejer G.J., Jäger H.J. (1992) Impact of climate change on agriculture - Open-top chambers as a tool to investigate long-term effects of elevated $\mathrm{CO}_{2}$ levels on plants, J. Appl. Bot. 66, 135-142. 